\title{
Associations of periparturient plasma biochemical parameters, endometrial leukocyte esterase and myeloperoxidase, and bacterial detection with clinical and subclinical endometritis in postpartum dairy cows
}

\author{
Sayed Ahmad NAZHAT ${ }^{1,2)}$, Go KITAHARA ${ }^{1,2)}$, Nobutoshi KOZUKA ${ }^{2)}$, \\ Shogo MIDO ${ }^{1,2)}$, Mohammed SADAWY ${ }^{2,3)}$, Hossam El-Sheikh ALI',4) and \\ Takeshi OSAWA ${ }^{1,2) *}$ \\ ${ }^{1)}$ Graduate School of Medicine and Veterinary Medicine, University of Miyazaki, Kihara 5200, Kiyotake, \\ Miyazaki, Miyazaki 889-1692, Japan \\ ${ }^{2)}$ Laboratory of Theriogenology, Department of Veterinary Sciences, Faculty of Agriculture, \\ University of Miyazaki, Gakuen-kibanadai Nishi 1-1, Miyazaki, Miyazaki 889-2192, Japan \\ ${ }^{3)}$ Theriogenology Department, Faculty of Veterinary Medicine, Assiut University, Assiut, Egypt \\ 4)Theriogenology Department, Faculty of Veterinary Medicine, Mansoura University, Mansoura, Egypt
}

J. Vet. Med. Sci.

80(2): 302-310, 2018

doi: 10.1292/jvms.17-0478

Received: 27 August 2017

Accepted: 3 December 2017

Published online in J-STAGE:

12 January 2018
ABSTRACT. This study was aimed at demonstrating associations between peripheral biochemical parameters, endometrial leukocyte esterase (LE) and myeloperoxidase (MPO), and bacterial detection with the degree of endometrial inflammation, and determining the best time postpartum for diagnosing endometritis to predict subsequent fertility in dairy cows. Plasma albumin, blood urea nitrogen (BUN), total cholesterol (T-cho), NEFA, and BHBA concentrations were analyzed in 43 Holstein cows at 3, 5 and 7 weeks postpartum (W3, W5 and W7). Endometrial samples were collected at W3, W5 and W7 to examine LE and MPO activities, bacterial detection rates, and PMN\% profiles. The 43 cows were divided into healthy (HE), subclinical endometritis (SE), and clinical endometritis (CE) groups, classified differently at W3, W5 and W7 based on the definitions of SE and CE for each of the three weeks pp. LE level had an association with PMN\% in all weeks pp $(P<0.05)$. Albumin and BUN levels had weak negative associations with endometrial $\mathrm{PMN} \%$ at W3. Pathogenic bacterial detection rates were higher in the cows with endometritis at W3 and W5. Conception rate at first artificial insemination tended to be lower $(P=0.057)$ in the cows diagnosed with endometritis at W3 than in the healthy cows. In conclusion, associations were found between endometrial LE and endometritis, but not for MPO and endometritis. Diagnosing endometritis in W3 may be the best moment to predict subsequent fertility.

KEY WORDS: biochemical parameter, cow, endometritis, leukocyte esterase, myeloperoxidase

High-yielding dairy cows experience metabolic stress during the early postpartum period, and consequently, are more susceptible to metabolic-related diseases, such as metritis or endometritis. Endometritis is the localized inflammation of the endometrium persisting beyond normal uterine involution, and has been documented to be a major limitation on the optimal reproductive performance of dairy cows $[2,32]$. Cows with microbial infections of the genital tract experience an inhibitory effect on the growth rate of dominant follicles, have a lower peripheral plasma estradiol or progesterone concentration, and are less likely to ovulate [38]. Economically, the calving interval will be extended because of the increase in days open, and hence, reduced milk production. Therefore, establishing the diagnosis of clinical and subclinical endometritis during the early postpartum period is important, because it could mitigate negative effects on reproductive performance, and hence, maximize the benefits gained from improved reproductive performance.

Pregnancy and lactation are two important physiological processes considered to be affected by metabolic stress. Plasma proteins, including albumin, act as carriers for the transport of substances, such as fatty acids, during inflammation [28], and

*Correspondence to: Osawa, T.: osawa@cc.miyazaki-u.ac.jp

O2018 The Japanese Society of Veterinary Science

This is an open-access article distributed under the terms of the Creative Commons Attribution Non-Commercial No Derivatives (by-nc-nd) License. (CC-BY-NC-ND 4.0: https://creativecommons.org/licenses/by-nc-nd/4.o/) 
blood urea nitrogen (BUN) levels reflect protein metabolism in dairy cows [9]. Previous studies have reported that there is a relationship between uterine diseases and concentrations of albumin, BUN, and total cholesterol [16, 22, 35]. Most dairy cows experience a negative energy balance status close to and after calving, and the concentrations of non-esterified fatty acids (NEFA) and ketone bodies increase substantially after calving [3, 34]. Elevated serum beta-hydroxybutyric acid (BHBA) concentrations in the first 2 weeks postpartum indicate an increased risk of metritis [14], which is a usual precursor of the development of clinical and subclinical endometritis [36]. However, previous studies have focused only on peripheral polymorphonuclear neutrophil (PMN) functions regarding the effects of these biochemical metabolites on immune functions around parturition; however, a clear relationship between local immunity in the uterus and biochemical parameters remains unknown.

Recently, the determination of the activity of leukocyte esterase (LE), an enzyme produced from neutrophils, has been proposed as a cow-side test for diagnosing postpartum subclinical endometritis. Hereby, test strips are able to analyze LE activity in urine samples as well as in uterine lavage fluid or uterine cytobrush samples $[10,12]$. Another important enzyme secreted by leukocytes is myeloperoxidase (MPO). MPO is a member of the mammalian peroxidase family, and is known to be effective in killing microorganisms [19]. Parrilla-Hernandez et al. [29] determined MPO levels in uterine lavage samples collected from mares, and proved that increased MPO concentrations were related to the occurrence of endometritis. However, to our knowledge, MPO levels in uterine fluid collected from cows have not been determined yet.

Another diagnostic technique for endometritis is the identification of bacterial species isolated from the uterus. The uteri of more than $90 \%$ of dairy cows are contaminated with bacteria in the first 2 weeks after parturition [31]. Although most cows combat this uterine bacterial contamination within 5 weeks postpartum (W5), bacterial infections resulting in endometritis occur in more than $10 \%$ of the animals [6]. In particular, bacterial species such as Trueperella pyogenes (T. pyogenes) and Escherichia coli (E. coli) have been reported to be pathogenic to the uterus [37]. Subclinical endometritis due to bacterial infections is known to affect the reproductive performance of cows [26]. Nevertheless, a clear relation between the detection rates of bacteria and severity of uterine inflammation has not been established.

Several diagnostic techniques for detecting the occurrence of inflammatory processes in the uterus, including ultrasonography [2], culture of bacteria from uterine fluid [7], uterine biopsy [5], and uterine cytology, have been described [17]. Ultrasonography and culture of bacteria from uterine fluid have been reported to have low sensitivity, and uterine biopsy followed by histological examination is expensive, time-consuming, and clinically inaccessible under practical field conditions. However, endometrial cytology using cytobrush techniques has recently been developed as a method useful for diagnosing clinical and subclinical endometritis in cows. Additionally, the determination of the percentage of polymorphonuclear neutrophils (PMN\%) is an objective method that can evaluate the extent of local inflammation within the uterus [1], since the occurrence of cytologically confirmed endometritis has been reported to have a detrimental effect on subsequent postpartum fertility [13]. It is of considerable importance to be able to correctly diagnose postpartum endometritis using validated cow-side techniques to improve the reproductive performance of dairy cows.

We hypothesized that blood-related biochemical parameters, LE and MPO levels, and/or isolation of bacterial species may be used as potential diagnostic markers for clinically detecting the occurrence of clinical and subclinical endometritis in postpartum dairy cows. Additionally, it is important to know the optimal time for diagnosing endometritis at the earliest to predict the fertility status of dairy cows. Therefore, the aims of this study were: 1 , to determine the relationship between the periparturient plasma levels of albumin, BUN, NEFA, BHBA, and T-cho, postpartum activities of leukocyte esterase (LE) and myeloperoxidase (MPO), as well as bacterial species in the endometrium and clinical and subclinical endometritis; 2, to determine the optimal postpartum time for detecting the occurrence of clinical and subclinical endometritis to predict the subsequent fertility status of dairy cows.

\section{MATERIALS AND METHODS}

\section{Animals}

Totally, 59 multiparous Holstein-Friesian cows from a dairy farm in Miyazaki Prefecture, Japan, were enrolled in this study. All cows were housed in free stalls, fed twice daily with a total mixed ration meeting the requirements for milk production with ad libitum access to water, and milked twice daily with an average milk production of $10,438 \mathrm{~kg}$ each cow per lactation. All cows were examined at 3, 5 and 7 weeks postpartum (W3, W5 and W7) by transrectal ultrasonography using Honda HS-1600V (Honda Electronics Co., Ltd., Toyohashi, Japan) to evaluate uterine conditions, such as the presence or absence of fluid in the uterine lumen, and ovarian conditions for the presence or absence of corpus luteum (CL) and large visible follicles. Totally, 16 cows, which were diagnosed as having pyometra $(n=9)$, culled $(n=5)$ due to other reasons, such as mastitis, or those that died $(n=2)$ by W7, were excluded from the study; the remaining 43 cows were used in this study. All cows had normal parturition, and none of them exhibited retained placenta. The cows were artificially inseminated after estrus detection after a voluntary waiting period of 55 days postpartum. The diagnosis of pregnancy was established by a skilled practitioner using transrectal ultrasonography within 30-43 days after artificial insemination (AI).

\section{Body condition score and vaginal mucus score}

The cows were examined for body condition score (BCS) at W3, W5 and W7. The BCS of each cow was evaluated on a 5-point scale with increments of 0.25 , as described by Ferguson et al [15]. Vaginal mucus discharge was scored (VMS) using a mucuscollecting device (Metricheck, Simcro Tech, Hamilton, New Zealand) at W3, W5 and W7 according to a method described by William et al. [37]: clear mucus was scored 0; mucus containing flecks of white pus was scored 1; discharge containing equal to 
or less than $50 \%$ of white mucopurulent material was scored 2 ; discharge containing equal to or more than $50 \%$ of white or yellow pus was scored 3 ; discharge containing $>50 \%$ of white or yellow pus along with fetid odor was scored 4 .

\section{Blood sampling and measurement of plasma biochemical parameters}

Blood samples were collected from the coccygeal vein at W3, W5 and W7 using vacuum tubes with EDTA (Terumo Co., Tokyo, Japan), and transported to the laboratory at $4^{\circ} \mathrm{C}$. Within $3 \mathrm{hr}$ of collection, plasma was separated by centrifugation at $1,500 \mathrm{~g}$ for $15 \mathrm{~min}$, harvested, and stored at $-20^{\circ} \mathrm{C}$ until further analysis. The following biochemical parameters were evaluated: albumin level by the Bromocresol Green method, BUN by the Urease-GLDH method, and T-cho, NEFA and BHBA levels by enzymatic analyses. The measurements were performed on a BioMajesty autoanalyzer (JCA-BM8060, JEOL Ltd., Tokyo, Japan).

\section{Collection of endometrial samples and cytological assessment}

Endometrial samples were collected at W3, W5 and W7 using the cytobrush technique, as described by Kasimanickam et al [23]. In brief, the regions of the perineum and vulva were washed, and wiped with a paper towel. A cytobrush (Metribrush, Fujihira Industry Co., Ltd., Tokyo, Japan) was threaded onto a $65-\mathrm{cm}$-long plastic rod, and placed in a stainless steel tube $(50 \mathrm{~cm}$ in length and $5 \mathrm{~mm}$ in diameter) for passage through the cervix. The instrument was placed in a sanitary plastic sleeve (Fujihira Industry Co., Ltd.) for the protection of vaginal contamination. Endometrial cytology samples were collected by rotating cytobrush against the endometrial epithelium in a clockwise direction while in contact with the uterine wall. The cytobrush was retracted into the stainless steel tube prior to removal from the uterus. For cytological assessment two slide glasses were prepared by rolling the cytobrush on a predetermined surface area of the glass and immediately fixed the slides on site using a cytofixative alcohol spray (Cytokeep ${ }^{\circledR}$ II, Alfresa Pharma Corp., Osaka, Japan) allowing the slides to dry, and staining using the Diff-Quik stain (Sysmex Corp., Kobe, Japan) for one min. Cytological assessment was performed by counting a minimum of 200 cells at $400 \times$ magnification to determine the percentage of neutrophils (PMN\%), as described previously [8, 27]. Initially, the entire slide was analyzed, and a representative area was selected to determine PMN\% [23].

\section{Evaluation of activities of leukocyte esterase and myeloperoxidase in the endometrium}

Endometrial samples were collected using the cytobrush, and rolled onto glass slides. In brief, the cytobrush was immersed in $1.5 \mathrm{~m} l$ of $0.9 \%$ saline contained in $2-\mathrm{m} l$ tubes, and agitated 20 times. Reagent test strips (Siemens Lifestix ${ }^{\circledR}$, Siemens Healthcare Co., Ltd., Tokyo, Japan) used for detecting and evaluating LE activity were inserted into the tubes for 5 sec, and the samples that remained were centrifuged at $600 \mathrm{~g}$ for $10 \mathrm{~min}$ to collect the supernatant, which was stored at $-20^{\circ} \mathrm{C}$ until the analysis of myeloperoxidase activity. The levels of LE activity were scored from code 0 to 4 based on the degree of color change observed on the strips as the esterase hydrolyzed its substrate (3-hydroxy-5-phenylpyrrole esterified with an amino acid) releasing 3-hydroxy-5phenylpyrrole, which in turn, reacted with a suitable diazonium salt, yielding a violet azo-dye [25]. The scores were: code $0,-$ (no leukocyte); code 1, \pm (traces of leukocytes); code 2, + (low number of leukocytes); code 3, ++ (moderate number of leukocytes); code 4, +++ (high number of leukocytes), as described previously [12] according to the manufacturer's instruction. Endometrial samples were collected randomly from 13 of 43 cows to measure MPO activity using a commercial bovine ELISA kit (ELISA kit for Myeloperoxidase, \#SEA601Bo, Cloud-Clone Corp., Houston, TX, U.S.A). The sensitivity and intra- and inter-assay coefficients of variation for the assay were $0.62 \mathrm{ng} / \mathrm{ml},<10$ and $<12 \%$, respectively.

\section{Isolation of bacteria}

Bacteriological samples were collected using sterilized cotton swabs rolled along the cytobrush, and placed in vials containing Amies charcoal medium (Hoei Co., Ltd., Osaka, Japan) cooled to $4-6^{\circ} \mathrm{C}$, and transported to the laboratory within $3 \mathrm{hr}$ after sample collection. The collected sample material was then transferred directly from the swab onto a standard blood agar medium (TryptoSoya Agar, Nissui Co., Tokyo, Japan) to culture aerobic and anaerobic bacteria for $48 \mathrm{hr}$ at $37^{\circ} \mathrm{C}$ under aerobic and anaerobic conditions, respectively. The bacterial species were identified based on colony morphology, Gram-stained smears, and biochemical characteristics [37]. The bacterial species were classified based on their pathogenicity: 1, T. pyogenes and E. coli (pathogenic bacteria) related to endometritis; 2, non-pathogenic bacteria [38]. Bacterial detection rate was calculated as the percentage of animals infected with bacteria, and pathogenic bacterial detection rate was calculated as the percentage of animals infected with pathogenic bacteria.

\section{Classification of animals}

The total number of 43 cows were divided into healthy (HE), subclinical endometritis (SE), and clinical endometritis (CE) groups. The diagnosis of clinical and subclinical endometritis was made based on endometrial PMN\% and VMS, and animals have been classified based on these two indices in previous studies [13, 37]. Therefore, in this study, the animals were classified based on PMN\% and vaginal mucus score, which changes each week postpartum. Classified animals were distributed in one of the three groups for endometritis status (HE, SE and CE) at W3, W5 and W7 to identify the most optimal moment postpartum to predict subsequent fertility outcome according to the previously accepted criteria: at W3, HE ( $\mathrm{n}=18), \mathrm{SE}(\mathrm{n}=8)$, and CE ( $\mathrm{n}=17)$ were defined as the conditions when PMN\% and VMS were $<18$ and $0-2, \geq 18$ and $0-2$, and $\geq 18$ and 3-4, respectively for [23]; at W5, HE $(n=26)$, SE $(n=8)$, and CE $(n=9)$ were defined as the conditions when PMN $\%$ and VMS were $<6$ and $0-1, \geq 6$ and $0-1$, and $\geq 6$ and $2-4$, respectively [13]; at $\mathrm{W} 7, \mathrm{HE}(\mathrm{n}=31), \mathrm{SE}(\mathrm{n}=9)$ and $\mathrm{CE}(\mathrm{n}=3)$ were defined as the conditions when PMN\% and VMS were $<4$ and $0-1, \geq 4$ and $0-1$, and $\geq 4$ and $2-4$, respectively [13]. 
Table 1. Pearson's correlation coefficients ( $r$ ) of relationships between PMN\%, biochemical parameters, and body condition scores in postpartum dairy cows $(n=43)$

\begin{tabular}{|c|c|c|c|c|c|c|}
\hline \multirow{3}{*}{$\begin{array}{l}\text { Biochemical } \\
\text { parameters }\end{array}$} & \multicolumn{6}{|c|}{ Week postpartum } \\
\hline & \multicolumn{2}{|c|}{ W3 } & \multicolumn{2}{|c|}{ W5 } & \multicolumn{2}{|c|}{ W7 } \\
\hline & $r$ & $P$ & $r$ & $P$ & $r$ & $P$ \\
\hline Albumin & -0.28 & 0.07 & -0.14 & 0.35 & -0.12 & 0.54 \\
\hline BUN & -0.28 & 0.07 & -0.20 & 0.19 & -0.32 & 0.08 \\
\hline T-cho & -0.21 & 0.19 & 0.01 & 1.00 & -0.24 & 0.19 \\
\hline NEFA & 0.03 & 0.85 & -0.08 & 0.60 & 0.01 & 0.96 \\
\hline BHBA & -0.06 & 0.72 & -0.18 & 0.24 & -0.16 & 0.38 \\
\hline BCS & -0.24 & 0.13 & -0.20 & 0.21 & -0.11 & 0.54 \\
\hline
\end{tabular}

$P=0.07$ and $P=0.08$ values show tendency toward negative correlation. The levels of blood albumin, blood urea nitrogen (BUN), Total cholesterol (T-cho), non-esterified fatty acid (NEFA), and $\beta$-hydroxybutyric acid (BHBA) were analyzed biochemically and body condition scores (BCS) were evaluated at weeks 3, 5 and 7 postpartum (W3, W5 and W7).

\section{Statistical analysis}

Data were analyzed using SPSS Statistics ${ }^{\circledR} 16.0$ (Version 16.0 released 2007, SPSS Inc., Chicago, IL, U.S.A.). One-way ANOVA was performed to compare the groups. A chi-square test was performed to compare bacterial detection rate with subsequent reproductive performance (days postpartum and conception rate at first AI). The levels of significance and tendency were set at $P<0.05$ and $0.05<P<0.1$, respectively.

\section{RESULTS}

\section{Relationship between plasma biochemical parameters and endometrial inflammation in postpartum dairy cows}

The relationship between plasma biochemical parameters and endometrial PMN\% in postpartum dairy cows is shown in Table 1. A weak negative association was demonstrated between albumin concentration at W3 and PMN\% $(P=0.07)$ (Fig. 1). Similarly, a weak negative association was observed between BUN level and PMN\% at both W3 $(P=0.07)$ and $\mathrm{W} 7(P=0.08)$. Out of the 7 cows that showed low albumin concentrations $(<2.5 \mathrm{~g} / \mathrm{d} l)$ [36] at W3, $5(71.4 \%)$ had high PMN\% (>18) (Table 2). Out of the 10 cows that showed low BUN levels $(<9 \mathrm{mg} / \mathrm{d} l)[24]$ at W3 and W7, $6(60 \%)$ had high PMN\% (>18). No relationship was observed between the concentrations of T-cho, NEFA and BHBA and BCS with PMN\%.

\section{Association of activities of leukocyte esterase (LE) and myeloperoxidase (MPO) with PMN in endometrial samples}

LE activity correlated significantly with PMN\% at W3, W5 and W7 ( $P<0.01)$ (Fig. 2). Contrarily, the association between MPO level and PMN\% was not significantly different at W3, W5 and W7.

\section{Bacterial detection rates}

A tendency was observed in the difference in bacterial detection rate as well as pathogenic bacterial detection rate between the $\mathrm{HE}$ and $\mathrm{CE}$ cow groups at W3 ( $P=0.055$, Fig. 3). Moreover, a significant difference in bacterial detection rate as well as pathogenic bacterial detection rate was observed between the HE and SE groups at W5 $(P<0.05)$. No differences were observed between groups $\mathrm{HE}, \mathrm{SE}$, and $\mathrm{CE}$ in at $\mathrm{W} 7$.

\section{Subsequent reproductive performance}

The conception rates at first AI in the HE group tended to be higher than those in the SE group, although not in the CE group at W3 $(P=0.057)$ (Table 3). No significant differences were observed in subsequent reproductive performance among the three groups at $\mathrm{W} 5$ and $\mathrm{W} 7$.

\section{DISCUSSION}

We demonstrated the relationships between peripheral biochemical parameters and activities of endometrial leukocyte esterase (LE) and myeloperoxidase (MPO) and the degree of endometrial inflammation, and determined the best time for diagnosing endometritis to predict subsequent fertility. Our study demonstrated weak associations between plasma albumin levels and endometrial PMN\% at W3 $(P=0.07)$ and between BUN levels and endometrial PMN\% at W3 $(P=0.07)$ and $\mathrm{W} 7(P=0.08)$, and LE activity had significant associations with PMN\% at W3, W5, and W7. The bacterial detection rate tended to be higher in CE and SE groups than in HE group at W3 $(P=0.055)$ and W5 $(P<0.05)$, and the conception rates at first $\mathrm{AI}$ in $\mathrm{HE}$ groups tended to be higher than those in SE group at W3 $(P=0.057)$.

A weak negative association was observed between albumin levels and PMN counts at W3. Albumin level was observed to be associated with postpartum disease, and can be used to predict disease risk in close-up and fresh cows [35]. Since total protein and 

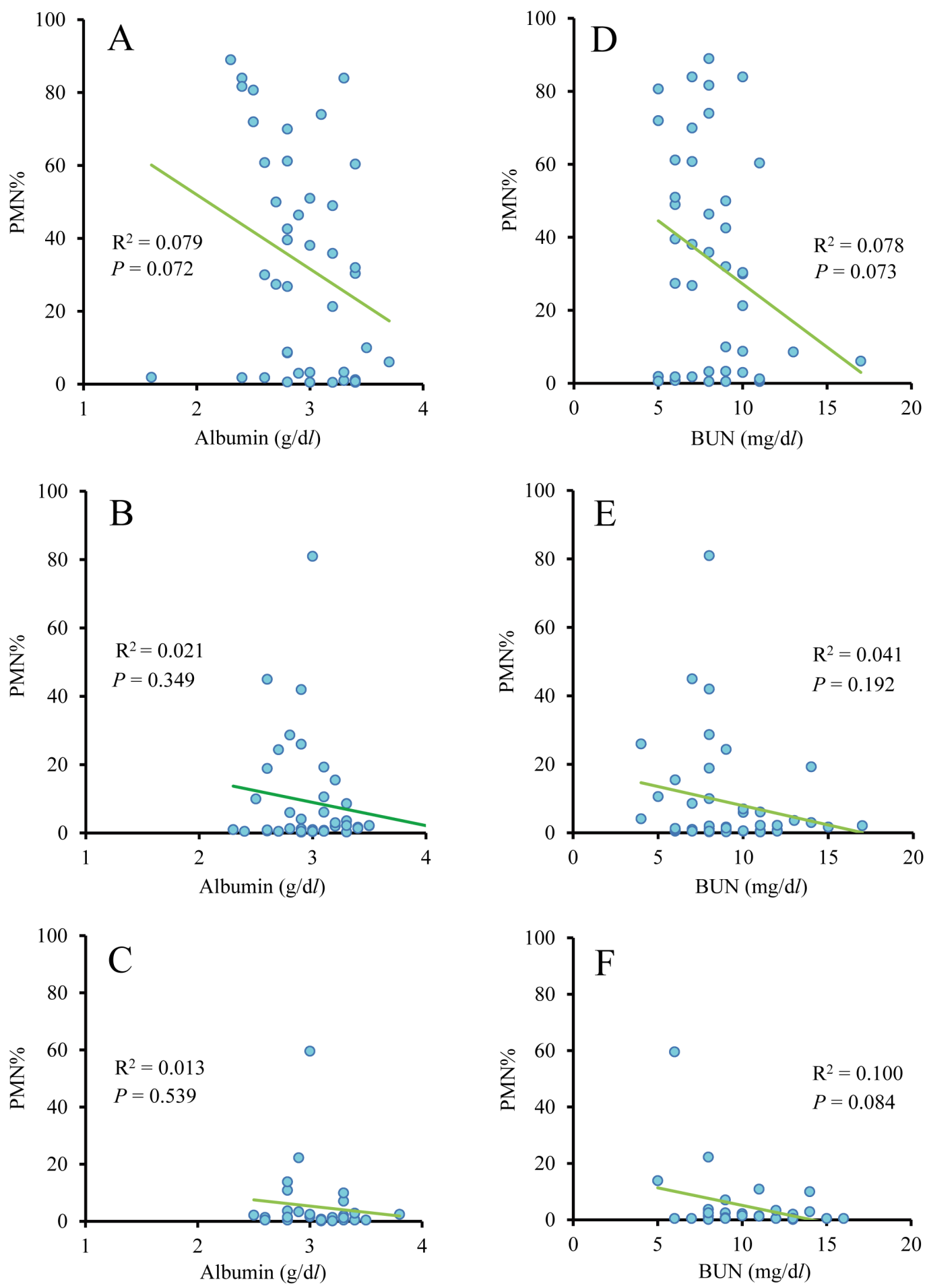

Fig. 1. Associations of albumin and BUN levels with $\mathrm{PMN} \%$ in endometrial samples from dairy cows ( $\mathrm{n}=43$ ). Graphs $\mathrm{A}$ to $\mathrm{C}$ show the associations between albumin levels and PMN\% at W3 (A), W5 (B) and W7 (C). Graphs D to F show the associations between BUN levels and PMN\% at W3 (D), W5 (E) and W7 (F).

albumin levels reflect the availability of protein, and since, consequently, their concentrations decline during protein deficiency, fresh cows with low plasma albumin $(<2.5 \mathrm{~g} / \mathrm{d} l)$ concentrations may fail to respond adequately to disease insults, and may suffer from metritis, mastitis, and other diseases [35]. The normal range of albumin concentration in healthy cows is $2.8-3.9 \mathrm{~g} / \mathrm{d} l$ [33] and $5 \mathrm{of}$ the $7(71.4 \%)$ cows with an albumin level $<2.5 \mathrm{~g} / \mathrm{d} l$ had high PMN\% at W3 in this study. Albumin is known to be a negative reacting protein, and its level decreases during inflammation $[4,28]$. This may be a reason for the low albumin concentrations in the cows with endometrial inflammation or high PMN\%. Albumin at low levels may serve as a marker for the development of endometritis. 
Table 2. Percentage of animals with low and high levels of albumin and blood urea nitrogen (BUN) in relation to low and high endometrial polymorphonuclear neutrophil (PMN) percentages in postpartum dairy cows

\begin{tabular}{|c|c|c|c|c|c|c|c|c|c|}
\hline \multirow{3}{*}{$\begin{array}{c}\text { Week } \\
\text { postpartum }\end{array}$} & \multicolumn{3}{|c|}{ W3 } & \multicolumn{3}{|c|}{ W5 } & \multicolumn{3}{|c|}{ W7 } \\
\hline & \multicolumn{3}{|c|}{ PMN (\%) } & \multicolumn{3}{|c|}{ PMN (\%) } & \multicolumn{3}{|c|}{ PMN (\%) } \\
\hline & $(n=43)$ & $\leq 18$ & $>18$ & $(n=43)$ & $\leq 6$ & $>6$ & $(n=43)$ & $\leq 4$ & $>4$ \\
\hline \multirow{2}{*}{ Albumina) } & Low $(n=7)$ & $2(28.5)$ & $5(71.4)$ & Low $(\mathrm{n}=0)$ & 0 & 0 & Low $(n=1)$ & 1 & 0 \\
\hline & High $(n=36)$ & $18(50)$ & $18(50)$ & High $(n=43)$ & $32(74.4)$ & $11(25.5)$ & High $(n=42)$ & $39(92.8)$ & $3(7.14)$ \\
\hline \multirow[t]{2}{*}{$\mathrm{BUN}^{\mathrm{b})}$} & Low $(n=10)$ & $4(40)$ & $6(60)$ & Low $(n=23)$ & $12(52.1)$ & $11(47.8)$ & Low $(n=10)$ & $4(40)$ & $6(60)$ \\
\hline & High $(n=33)$ & $18(54.5)$ & $15(45.4)$ & $\operatorname{High}(\mathrm{n}=20)$ & $19(95)$ & $1(5)$ & $\operatorname{High}(\mathrm{n}=33)$ & $32(97)$ & $1(3)$ \\
\hline
\end{tabular}

a) The threshold for low albumin level was $<2.5 \mathrm{~g} / \mathrm{d} l$; b) The threshold for low BUN level was $<9.0 \mathrm{mg} / \mathrm{d} l[24,35]$.

In our study, we observed weak negative associations between BUN levels and PMN\% at W3 and W7. Of the 10 (60\%) cows with low BUN levels $(<9 \mathrm{mg} / \mathrm{d} l)$, which was far below the normal range of BUN levels in healthy cows $(12.8-57.7 \mathrm{mg} / \mathrm{d} l)$ [33], 6 had high PMN\% (over 80) at W3 and W7. This finding, which was consistent with that of a previous study, showed that cows with low BUN levels $(<9 \mathrm{mg} / l)$ at W2 and W4 are at a risk of developing endometritis by W5 and W6, respectively [30]. Another report stated that cows with low BUN levels and high PMN\% may have consumed lower DMI during the transition period than healthy cows [21], which is necessary for minimizing negative energy balance and maintaining animal health.

There were no associations between the other biochemical parameters and PMN\%. Since acute-phase proteins may be useful parameters for the prognosis of endometritis [20], their effect on PMN function in pre- and postpartum cows should be clarified in future.

There were positive associations between LE levels and endometrial PMN\% at W3, W5 and W7. The result of this study that LE activity increased significantly in the cows with subclinical endometritis [10,12] agreed with those of previous studies, and showed that the association was the strongest, and many cows had high PMN\% at W3, because neutrophils were present at greater numbers than at W5 and W7. Cows in the early postpartum period tend to have extremely high proportions of neutrophils in endometrial cytology [17], which may have helped in improving the sensitivity of the reagent strip test. Although there is no previous report clarifying the relationship between LE and endometrial PMN at such an early postpartum period as W3, our results suggested that the collection of endometrial samples in this period for evaluating LE activity may be valuable for diagnosing subclinical endometritis.

To the best of our knowledge, this is the first study on MPO levels in the endometrium of cows, although high MPO levels in milk has been reported to be related to high somatic cell numbers and neutrophil count in cows [11]. Mares with positive cytology had significantly high MPO levels [29]. However, in the present study, there was no such association between MPO level and $\mathrm{PMN} \%$ in the dairy cow. One possible explanation for this discrepancy between the findings of the previous study and the present study may emerge from the differences in the estrous cycle. While endometrial samples were collected from mares during estrus in the previous study, samples were collected from cows during the early postpartum period regardless of the estrous cycle in the present study. Moreover, we randomly chose a limited number of cows to conduct a preliminary assay. Further investigations, such as studies clarifying MPO profiles during the estrous cycle in cows, are required to confirm whether MPO levels change with the stage of the estrous cycle.

Previous studies reported that among the bacterial species causing endometrial diseases (pathogenic to the endometrium), T. pyogenes and E. coli are the most prevalent $[18,37]$. This is the reason for our focus on these two bacterial species in our study. The detection rate of T. pyogenes or E. coli in the uterus tended to be higher in the clinical endometritis group than in the healthy group at W3. Similarly, the pathogenic bacterial detection rate was higher in the subclinical endometritis group than in the healthy group at W5. Usually, healthy cows get rid of bacteria from their uteri within approximately 3 weeks after calving, and complete uterine involution within 4 or 6 weeks [32], and those suffering from immunosuppression around calving owing to calving stress or with low DMI and high negative energy balance (NEB) are affected by endometritis. The uteri of postpartum dairy cows are susceptible to infection by different pathogenic bacterial species and infections appearing to be related to periparturient immunosuppression and negative energy balance around calving [14]. We conjectured that the detection rates of T. pyogenes and E. coli are regarded as important factors influencing the incidence of clinical and subclinical endometritis.

The conception rates at first AI tended to be higher in the HE group than in the SE group diagnosed at W3, although not at W5 or W7. The infection of the uterine lumen with pathogens suppresses follicular growth rate and consequently, the function of the first postpartum dominant follicle [38]. Therefore, subclinical endometritis due to bacterial infection prolongs the days to first service and calving-to-conception interval, and reduces pregnancy rate [26]. Kasimanickam et al. [23] reported a decrease in the proportion of pregnant cows, increased number of open days and reduced conception rates at first AI in cows with subclinical endometritis housed under intensive farming conditions. To the best of our knowledge, no previous study has reported the optimal time for diagnosing endometritis postpartum. Nevertheless, the diagnosis of endometritis in dairy cows in early postpartum as early as W3 after calving may be required to improve subsequent reproductive performance.

In summary, the findings of the present study confirmed that the relationship between the plasma biochemical parameters and LE levels with PMN\% as well as the pathogenic bacterial detection rates may be related to the occurrence of endometritis, diagnosed by cytological assessment as early as W3. It is concluded that there were associations between endometrial LE activity 

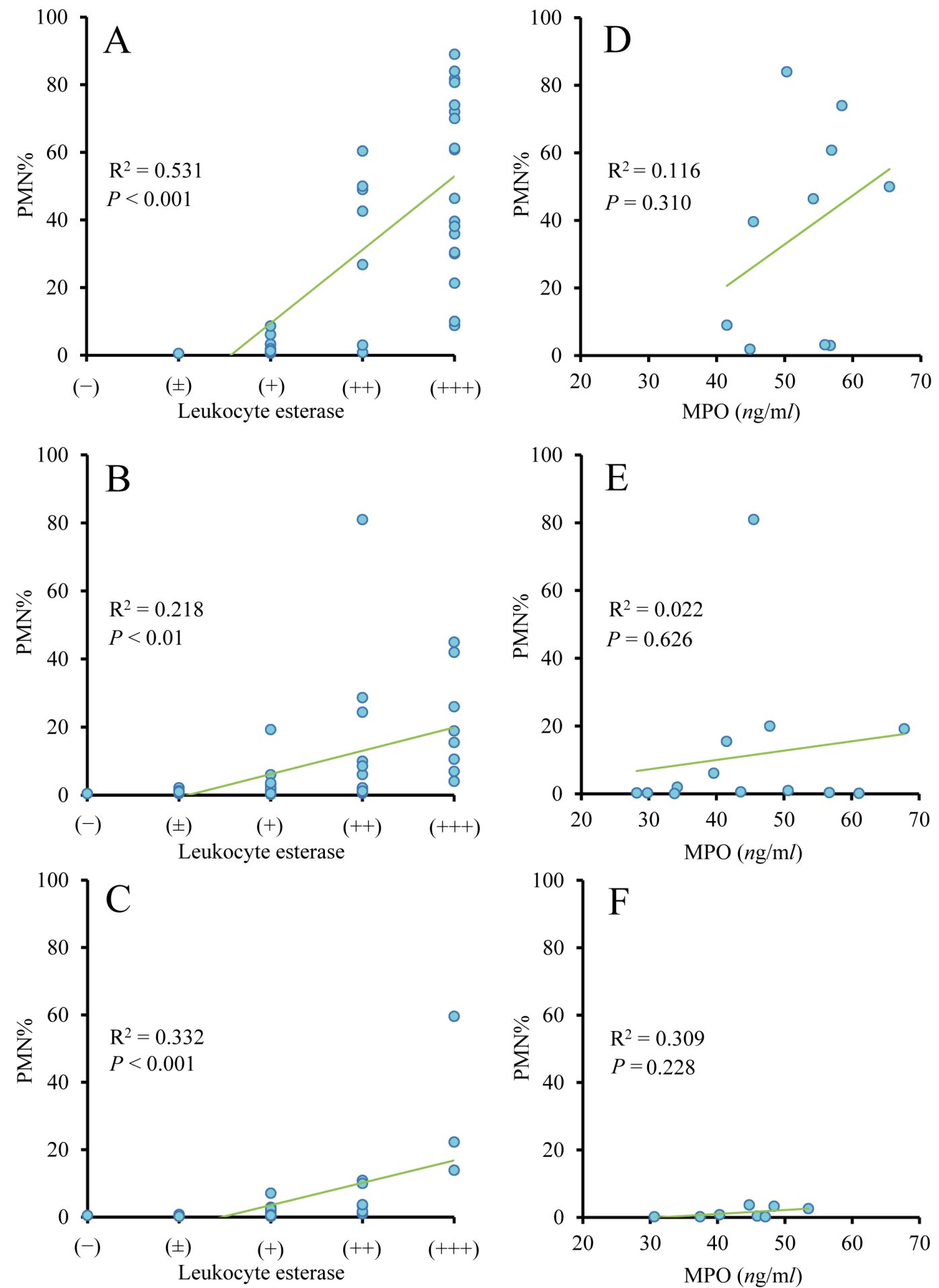

Fig. 2. Associations of levels of leukocyte esterase (LE) $(n=43)$ and myeloperoxidase (MPO) $(n=13)$ with PMN\% in endometrial samples from dairy cows. Graphs A to C show the associations between LE levels and PMN\% at W3 (A), W5 (B) and W7 (C). Graphs D to F show the associations between MPO levels and PMN\% at W3 (D), W5 (E) and W7 (F).

and endometritis, although not between MPO activity and endometritis, and W3 may be the best time for the early diagnosis of endometritis to predict subsequent fertility.

ACKNOWLEDGMENTS. We thank the members of the Miyazaki Prefecture Livestock Public Corporation for their cooperation on this research. This research was supported in part by a Grant-in-Aid for Scientific Research (No. 16H05038 to TO) from the Japan Society for the Promotion of Science. 


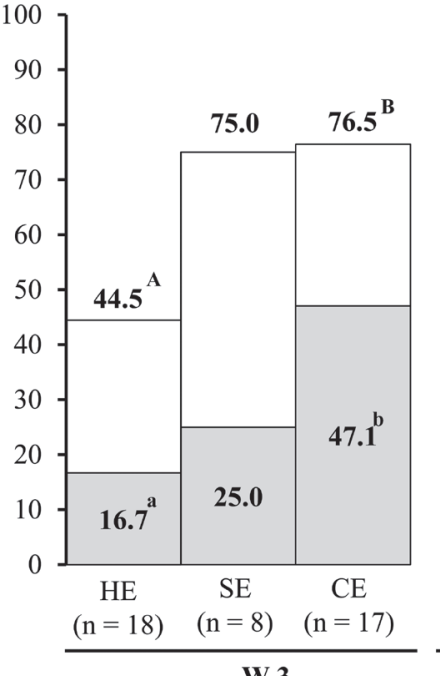

W 3

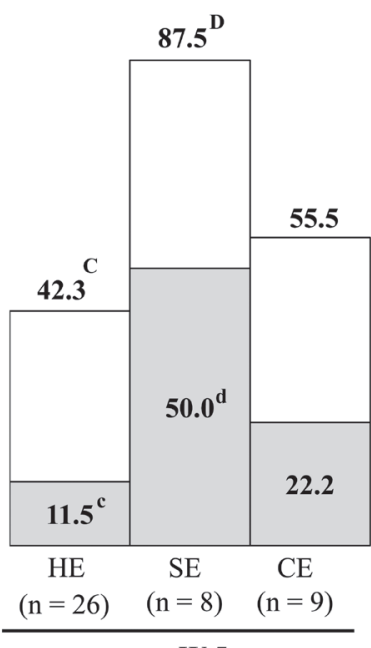

W 5

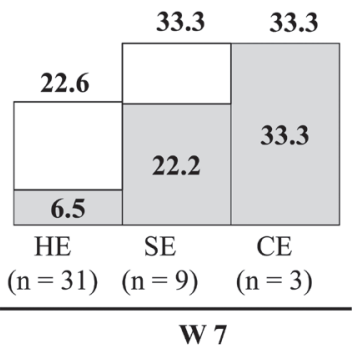

W 7

Fig. 3. Comparison of bacterial detection rates between healthy (HE), clinical endometritis (CE), and subclinical endometritis (SE) dairy cow groups $(n=43)$. The grey part of the bars indicates pathogenic bacteria detection rate and white part indicates nonpathogenic bacteria detection rate. The three groups were classified differently at W3, W5 and W7 based on the definitions of SE and CE for each of the following weeks pp: at W3, HE, SE and CE, were defined as the conditions when PMN\% and VMS were $<18$ and $0-2, \geq 18$ and $0-2$, and $\geq 18$ and 3-4, respectively; at W5, HE, SE and CE were defined as the conditions when PMN\% and VMS were $<6$ and $0-1, \geq 6$ and $0-1$, and $\geq 6$ and $2-4$, respectively; was at W7, HE, SE, and CE were defined as the conditions when PMN\% and VMS were $<4$ and $0-1, \geq 4$ and $0-1$, and $\geq 4$ and $2-4$, respectively. a-b, A-B: $P=0.055$; $\mathrm{c}-\mathrm{d}, \mathrm{C}-\mathrm{D}: P<0.05$.

Table 3. Comparison of subsequent reproductive performance between healthy cows, cows with subclinical endometritis and cows with clinical endometritis

\begin{tabular}{llcc}
\hline \multirow{2}{*}{ Week postpartum } & \multicolumn{1}{c}{ Group } & $\begin{array}{c}\text { Calving-to-first service } \\
\text { interval (days postpartum)* }\end{array}$ & $\begin{array}{c}\text { Conception rate } \\
\text { at first service (\%) }\end{array}$ \\
\hline W3 & Healthy (HE) (n=18) & $91.6 \pm 7.1$ & $43.8^{\text {a) }(7 / 16)}$ \\
& Subclinical endometritis (SE) $(\mathrm{n}=8)$ & $70.2 \pm 8.9$ & $0^{\text {b) }}(0 / 7)$ \\
& Clinical endometritis (CE) $(\mathrm{n}=17)$ & $86.1 \pm 11.9$ & $23.1(3 / 13)$ \\
\hline W5 & Healthy (HE) (n=26) & $89.6 \pm 8.5$ & $36.4(8 / 22)$ \\
& Subclinical endometritis (SE) (n=8) & $90.6 \pm 7.0$ & $33.3(2 / 6)$ \\
& Clinical endometritis (CE) (n=9) & $75.1 \pm 6.9$ & $0(0 / 8)$ \\
\hline W7 & Healthy (HE) (n=31) & $83.3 \pm 4.9$ & $29.6(8 / 27)$ \\
& Subclinical endometritis (SE) (n=9) & $97.8 \pm 22.4$ & $28.5(2 / 7)$ \\
& Clinical endometritis (CE) $(\mathrm{n}=3)$ & $72.0 \pm 8.0$ & $0(0 / 2)$ \\
\hline
\end{tabular}

a, b: $P=0.057 .{ }^{*}$ Data are expressed as mean \pm standard error of mean (SEM). The three groups were classified differently at W3, W5 and W7 based on the definitions of SE and CE for each of the following weeks pp: at W3, HE, SE and CE were defined as the conditions when PMN\% and VMS were $<18$ and $0-2, \geq 18$ and $0-2$, and $\geq 18$ and 3-4, respectively; at W5, HE, SE and CE were defined as the conditions when PMN\% and VMS were $<6$ and $0-1, \geq 6$ and $0-1$, and $\geq 6$ and $2-4$, respectively; at W7, HE, SE and CE were defined as the conditions when PMN $\%$ and VMS were $<4$ and $0-1, \geq 4$ and $0-1$, and $\geq 4$ and $2-4$, respectively. Out of the 43 cows, 7 cows with mastitis $(n=5)$ or those that died $(n=2)$ were excluded from reproductive performance analysis.

\section{REFERENCES}

1. Barański, W., Podhalicz-Dzięgielewska, M., Zduńczyk, S. and Janowski, T. 2012. The diagnosis and prevalence of subclinical endometritis in cows evaluated by different cytologic thresholds. Theriogenology 78: 1939-1947. [Medline] [CrossRef]

2. Barlund, C. S., Carruthers, T. D., Waldner, C. L. and Palmer, C. W. 2008. A comparison of diagnostic techniques for postpartum endometritis in dairy cattle. Theriogenology 69: 714-723. [Medline] [CrossRef]

3. Bertics, S. J., Grummer, R. R., Cadorniga-Valino, C. and Stoddard, E. E. 1992. Effect of prepartum dry matter intake on liver triglyceride concentration and early lactation. J. Dairy Sci. 75: 1914-1922. [Medline] [CrossRef]

4. Bertoni, G., Trevisi, E., Han, X. and Bionaz, M. 2008. Effects of inflammatory conditions on liver activity in puerperium period and consequences for performance in dairy cows. J. Dairy Sci. 91: 3300-3310. [Medline] [CrossRef]

5. Bonnett, B. N., Martin, S. W., Gannon, V. P., Miller, R. B. and Etherington, W. G. 1991. Endometrial biopsy in Holstein-Friesian dairy cows. III. Bacteriological analysis and correlations with histological findings. Can. J. Vet. Res. 55: 168-173. [Medline]

6. Borsberry, S. and Dobson, H. 1989. Periparturient diseases and their effect on reproductive performance in five dairy herds. Vet. Rec. 124: 217-219. 
[Medline] [CrossRef]

7. Bretzlaff, K. 1987. Rationale for treatment of endometritis in the dairy cow. Vet. Clin. North Am. Food Anim. Pract. 3: 593-607. [Medline] [CrossRef]

8. Burke, C. R., Meier, S., McDougall, S., Compton, C., Mitchell, M. and Roche, J. R. 2010. Relationships between endometritis and metabolic state during the transition period in pasture-grazed dairy cows. J. Dairy Sci. 93: 5363-5373. [Medline] [CrossRef]

9. Butler, W. R. 1998. Review: effect of protein nutrition on ovarian and uterine physiology in dairy cattle. J. Dairy Sci. 81: 2533-2539. [Medline] [CrossRef]

10. Cheong, S. H., Nydam, D. V., Galvão, K. N., Crosier, B. M., Ricci, A., Caixeta, L. S., Sper, R. B., Fraga, M. and Gilbert, R. O. 2012. Use of reagent test strips for diagnosis of endometritis in dairy cows. Theriogenology 77: 858-864. [Medline] [CrossRef]

11. Cooray, R. 1994. Use of bovine myeloperoxidase as an indicator of mastitis in dairy cattle. Vet. Microbiol. 42: 317-326. [Medline] [CrossRef]

12. Couto, G. B., Vaillancourt, D. H. and Lefebvre, R. C. 2013. Comparison of a leukocyte esterase test with endometrial cytology for diagnosis of subclinical endometritis in postpartum dairy cows. Theriogenology 79: 103-107. [Medline] [CrossRef]

13. Dubuc, J., Duffield, T. F., Leslie, K. E., Walton, J. S. and LeBlanc, S. J. 2010. Definitions and diagnosis of postpartum endometritis in dairy cows. J. Dairy Sci. 93: 5225-5233. [Medline] [CrossRef]

14. Duffield, T. F., Lissemore, K. D., McBride, B. W. and Leslie, K. E. 2009. Impact of hyperketonemia in early lactation dairy cows on health and production. J. Dairy Sci. 92: 571-580. [Medline] [CrossRef]

15. Ferguson, J. D., Galligan, D. T. and Thomsen, N. 1994. Principal descriptors of body condition score in Holstein cows. J. Dairy Sci. 77: $2695-2703$. [Medline] [CrossRef]

16. Ghanem, M. E., Tezuka, E., Sasaki, K., Takahashi, M., Yamagishi, N., Izaike, Y. and Osawa, T. 2016. Correlation of blood metabolite concentrations and body condition scores with persistent postpartum uterine bacterial infection in dairy cows. J. Reprod. Dev. 62: 457-463. [Medline] [CrossRef]

17. Gilbert, R. O., Shin, S. T., Guard, C. L., Erb, H. N. and Frajblat, M. 2005. Prevalence of endometritis and its effects on reproductive performance of dairy cows. Theriogenology 64: 1879-1888. [Medline] [CrossRef]

18. Griffin, J. F., Hartigan, P. J. and Nunn, W. R. 1974. Non-specific uterine infection and bovine fertility. I. Infection patterns and endometritis during the first seven weeks post-partum. Theriogenology 1: 91-106. [Medline] [CrossRef]

19. Guven, F. M., Aydin, H., Yildiz, G., Engin, A., Celik, V. K., Bakir, D. and Deveci, K. 2013. The importance of myeloperoxidase enzyme activity in the pathogenesis of Crimean-Congo haemorrhagic fever. J. Med. Microbiol. 62: 441-445. [Medline] [CrossRef]

20. Heidarpour, M., Mohri, M., Fallah-Rad, A. H., Dehghan Shahreza, F. and Mohammadi, M. 2012. Acute-phase protein concentration and metabolic status affect the outcome of treatment in cows with clinical and subclinical endometritis. Vet. Rec. 171: 219. [Medline] [CrossRef]

21. Huzzey, J. M., Veira, D. M., Weary, D. M. and von Keyserlingk, M. A. 2007. Prepartum behavior and dry matter intake identify dairy cows at risk for metritis. J. Dairy Sci. 90: 3220-3233. [Medline] [CrossRef]

22. Kaneene, J. B., Miller, R., Herdt, T. H. and Gardiner, J. C. 1997. The association of serum nonesterified fatty acids and cholesterol, management and feeding practices with peripartum disease in dairy cows. Prev. Vet. Med. 31: 59-72. [Medline] [CrossRef]

23. Kasimanickam, R., Duffield, T. F., Foster, R. A., Gartley, C. J., Leslie, K. E., Walton, J. S. and Johnson, W. H. 2004. Endometrial cytology and ultrasonography for the detection of subclinical endometritis in postpartum dairy cows. Theriogenology 62: 9-23. [Medline] [CrossRef]

24. Kaufmann, T. B., Drillich, M., Tenhagen, B. A. and Heuwieser, W. 2010. Correlations between periparturient serum concentrations of non-esterified fatty acids, beta-hydroxybutyric acid, bilirubin, and urea and the occurrence of clinical and subclinical postpartum bovine endometritis. BMC Vet. Res. 6: 47. [Medline] [CrossRef]

25. Kutter, D., Figueiredo, G. and Klemmer, L. 1987. Chemical detection of leukocytes in urine by means of a new multiple test strip. J. Clin. Chem. Clin. Biochem. 25: 91-94. [Medline]

26. LeBlanc, S. J., Duffield, T. F., Leslie, K. E., Bateman, K. G., Keefe, G. P., Walton, J. S. and Johnson, W. H. 2002. Defining and diagnosing postpartum clinical endometritis and its impact on reproductive performance in dairy cows. J. Dairy Sci. 85: 2223-2236. [Medline] [CrossRef]

27. Madoz, L. V., Giuliodori, M. J., Migliorisi, A. L., Jaureguiberry, M. and de la Sota, R. L. 2014. Endometrial cytology, biopsy, and bacteriology for the diagnosis of subclinical endometritis in grazing dairy cows. J. Dairy Sci. 97: 195-201. [Medline] [CrossRef]

28. Mazzaferro, E. M., Rudloff, E. and Kirby, R. 2002. The role of albumin replacement in the critically ill veterinary patient. J. Vet. Emergency and Critical Care Med. 12:113-124.

29. Parrilla-Hernandez, S., Ponthier, J., Franck, T. Y., Serteyn, D. D. and Deleuze, S. C. 2014. High concentrations of myeloperoxidase in the equine uterus as an indicator of endometritis. Theriogenology 81: 936-940. [Medline] [CrossRef]

30. Senosy, W. S., Izaike, Y. and Osawa, T. 2012. Influences of metabolic traits on subclinical endometritis at different intervals postpartum in high milking cows. Reprod. Domest. Anim. 47: 666-674. [Medline] [CrossRef]

31. Sheldon, I. M., Noakes, D. E., Rycroft, A. N., Pfeiffer, D. U. and Dobson, H. 2002. Influence of uterine bacterial contamination after parturition on ovarian dominant follicle selection and follicle growth and function in cattle. Reproduction 123: 837-845. [Medline] [CrossRef]

32. Sheldon, I. M., Lewis, G. S., LeBlanc, S. and Gilbert, R. O. 2006. Defining postpartum uterine disease in cattle. Theriogenology 65: $1516-1530$. [Medline] [CrossRef]

33. The Merck Veterinary Manual. 2010. 10th ed., Kahn, C. M. ed., Merck and Co., Inc., New Jersey.

34. Valergakis, G. E., Oikonomou, G., Arsenos, G. and Banos, G. 2011. Phenotypic association between energy balance indicators and reproductive performance in primiparous Holstein cows. Vet. Rec. 168: 189. [Medline] [CrossRef]

35. Van Sun, R. J. 2004. Metabolic profiling and health risk in transition cows. Proc. Am. Assoc. Bov. Pract. 37: 212-213.

36. Walsh, R. B., Walton, J. S., Kelton, D. F., LeBlanc, S. J., Leslie, K. E. and Duffield, T. F. 2007. The effect of subclinical ketosis in early lactation on reproductive performance of postpartum dairy cows. J. Dairy Sci. 90: 2788-2796. [Medline] [CrossRef]

37. Williams, E. J., Fischer, D. P., Pfeiffer, D. U., England, G. C., Noakes, D. E., Dobson, H. and Sheldon, I. M. 2005. Clinical evaluation of postpartum vaginal mucus reflects uterine bacterial infection and the immune response in cattle. Theriogenology 63: 102-117. [Medline] [CrossRef]

38. Williams, E. J., Fischer, D. P., Noakes, D. E., England, G. C., Rycroft, A., Dobson, H. and Sheldon, I. M. 2007. The relationship between uterine pathogen growth density and ovarian function in the postpartum dairy cow. Theriogenology 68: 549-559. [Medline] [CrossRef] 